\title{
AN OPERATOR EXTENSION OF THE PARALLELOGRAM LAW AND RELATED NORM INEQUALITIES
}

\author{
Mohammad Sal MosLehian
}

Abstract. We establish a general operator parallelogram law concerning a characterization of inner product spaces, get an operator extension of Bohr's inequality and present several norm inequalities. More precisely, let $\mathfrak{A}$ be a $C^{*}$-algebra, $T$ be a locally compact Hausdorff space equipped with a Radon measure $\mu$ and let $\left(A_{t}\right)_{t \in T}$ be a continuous field of operators in $\mathfrak{A}$ such that the function $t \mapsto A_{t}$ is norm continuous on $T$ and the function $t \mapsto\left\|A_{t}\right\|$ is integrable. If $\alpha: T \times T \rightarrow \mathbb{C}$ is a measurable function such that $\overline{\alpha(t, s)} \alpha(s, t)=1$ for all $t, s \in T$, then we show that

$$
\begin{gathered}
\int_{T} \int_{T}\left|\alpha(t, s) A_{t}-\alpha(s, t) A_{s}\right|^{2} d \mu(t) d \mu(s)+\int_{T} \int_{T}\left|\alpha(t, s) B_{t}-\alpha(s, t) B_{s}\right|^{2} d \mu(t) d \mu(s) \\
=2 \int_{T} \int_{T}\left|\alpha(t, s) A_{t}-\alpha(s, t) B_{s}\right|^{2} d \mu(t) d \mu(s)-2\left|\int_{T}\left(A_{t}-B_{t}\right) d \mu(t)\right|^{2} .
\end{gathered}
$$
$15 \mathrm{~A} 60$.

Mathematics subject classification (2010): Primary 47A63; Secondary 46C15, 47A30, 47B10, 47B15,

Keywords and phrases: Bochner integral, Schatten $p$-norm, norm inequality, parallelogram law, unitarily invariant norm, convex function, Bohr's inequality, inner product space.

\section{REFERENCES}

[1] S. Abramovich, J. Barić And J.E. PeČAriĆ, A new proof of an inequality of Bohr for Hilbert space operators, Linear Algebra Appl. 430, 4 (2009), 1432-1435.

[2] J.S. AuJla AND F.C. Silva, Weak majorization inequalities and convex functions, Linear Algebra Appl. 369 (2003), 217-233.

[3] W.-S. Cheung And J. PeČArić, Bohr's inequalities for Hilbert space operators, J. Math. Anal. Appl. 323, 1 (2006), 403-412.

[4] Y.J. Cho, V. ČUlJaK, M. Matić And J.E. PeČARić, On parallelogram law and Bohr's inequality in n-inner product spaces, Inequality theory and applications, Vol. 2 (Chinju/Masan, 2001), 79-90, Nova Sci. Publ., Hauppauge, NY, 2003.

[5] O. EĞECIOĞLU, Parallelogram-law-type identities, Linear Algebra Appl. 225 (1995), 1-12.

[6] M. Fujil AND H. ZHou, Matrix order in Bohr inequality for operators, Banach J. Math. Anal., 4, 1 (2010), 21-27.

[7] F. HANSEn, J.E. PeČARIĆ AND I. Perić, Jensen's operator inequality and its converses, Math. Scand. 100, 1 (2007), 61-73.

[8] F. Hansen And G.K. Pedersen, Jensen's operator inequality, Bull. London Math. Soc. 35 (2003), $553-564$.

[9] O. HirZallah, Non-commutative operator Bohr inequality, J. Math. Anal. Appl. 282 (2003), 578583.

[10] O. Hirzallah and F. Kittaneh, Non-commutative Clarkson inequalities for $n$-tuples of operators, Integral Equations Operator Theory 60, 3 (2008), 369-379.

[11] O. Hirzallah, F. Kittaneh And M.S. Moslehian, Schatten $p$-norm inequalities related to a characterization of inner product spaces, Math. Inequal. Appl. 13, 2 (2010), 235-241. 
[12] M. KATO, A note on a generalized parallelogram law and the Littlewood matrices, Bull. Kyushu Inst. Tech. Math. Natur. Sci. 33 (1986), 37-39.

[13] T. Kosem, Inequalities between $\|f(A+B)\|$ and $\|f(A)+f(B)\|$, Linear Algebra Appl. 418, 1 (2006), $153-160$.

[14] M.S. Moslehian, J.E. PeČAriĆ And I. Perić, An operator extension of Bohr's inequality, Bull. Iranian Math. Soc. 35, 2 (2009), 67-74.

[15] B. Simon, Trace Ideals and their Applications, Cambridge University Press, Cambridge, 1979.

[16] F. ZHANG, On the Bohr inequality of operators, J. Math. Anal. Appl. 333 (2007), 1264-1271.

[17] W.L.ZENG, An extension of the parallelogram characterization of inner product spaces, J. Math. Res. Exposition 2, 3 (1982), 23-25. 